\title{
Effect of Poly(propylene imine) Glycodendrimers on $\beta$-Amyloid Aggregation in Vitro and in APP/PS1 Transgenic Mice, as a Model of Brain Amyloid Deposition and Alzheimer's Disease
}

\author{
O. Klementieva, ${ }^{* \dagger}$ E. Aso, ${ }^{\dagger}$ D. Filippini, ${ }^{\ddagger}$ N. Benseny-Cases,${ }^{\S}$ M. Carmona, ${ }^{\dagger}$ S. Juvés, ${ }^{\dagger}$ D. Appelhans, ${ }^{\ddagger}$ \\ J. Cladera," and I. Ferrer*,t, \\ ${ }^{\dagger}$ Institute of Neuropathology, Pathologic Anatomy Service, IDIBELL-University Hospital Bellvitge, Feixa Llarga sn, 08907 \\ L'Hospitalet de Llobregat, Spain \\ ${ }^{\ddagger}$ Leibniz Institute of Polymer Research Dresden, Hohe Strasse 6, D-01069 Dresden, Germany \\ ${ }^{\S}$ Polygone Scientifique Louis Néel, ESRF, 6 rue Jules Horowitz, 38000, Grenoble, France \\ "Biophysics Unit and Center of Studies in Biophysics, Department of Biochemistry and Molecular Biology, Universitat Autònoma de \\ Barcelona (UAB), 08193 Bellaterra, Spain \\ ${ }^{\perp}$ Department of Pathology and Experimental Therapy, School of Medicine, University of Barcelona, L'Hospitalet de Llobregat, Spain \\ ${ }^{\#}$ CIBERNED, Instituto Carlos III, Madrid, Spain
}

ABSTRACT: Poly(propylene imine) (PPI) glycodendrimers are promising candidates as drug carriers and antiamyloidogenic and antiprionic agents. In this study the anti- $\beta$-amyloid capacity of PPI glycodendrimers of the fourth and fifth generations was investigated in vitro and in vivo. We assessed distinct PPI glycodendrimers including $\mathrm{G} 4 \mathrm{mDS}$ and $\mathrm{G} 5 \mathrm{mDS}$, with electroneutral maltose shell, and G4mOS and G4m-IIIOS, with cationic maltose or maltotriose shell. Our results show that in vitro PPI maltose dendrimers reduce the toxicity of $A \beta(1-42)$. However, only the electroneutral maltose dendrimers G4mDS and G5mDS reduce the toxicity of Alzheimer's disease brain extracts in $\mathrm{SH}-$ SY5Y neuroblastoma cells. PPI maltose dendrimers with electroneutral or cationic surface penetrate the cytoplasm of cultured cells, and they reach the brain when administered intranasally. Both cationic G4mOS and electroneutral G4mDS are able to modify the total burden of $\beta$-amyloid in APP/PS1 mice. The studied dendrimers did not reverse memory impairment in APP/ PS1 mice following chronic administration; moreover, cationic G4mOS caused cognitive decline in nontransgenic mice. In spite of the capacity of G4mDS and G4mOS to cross the blood-brain barrier and modulate $\mathrm{A} \beta$ aggregation in APP/PS1 mice, further studies are needed to learn how to reduce the harmful effects of maltose dendrimers in vivo.

\section{INTRODUCTION}

Alzheimer's disease $(\mathrm{AD})$ is a neurodegenerative process characterized by the progressive deposition of $\beta$-amyloid $(\mathrm{A} \beta)$ in the form of neuritic and diffuse plaques and $\mathrm{A} \beta$ angiopathy, as well as by hyperphosphorylated tau deposition in neurons, forming neurofibrillary tangles, dystrophic neurites, and neuropil threads. According to the $\mathrm{A} \beta$ cascade hypothesis, $\mathrm{A} \beta$ peptides play a central role in triggering neuronal damage in cerebral $\beta$-amyloidosis and most particularly in familial and sporadic $\mathrm{AD}$. Because soluble $\mathrm{A} \beta$ peptide oligomers, intermediates in the assembly of $A \beta$ fibrils, are more neurotoxic than fibrils, ${ }^{1-3}$ one possible action against the harmful effects of toxic soluble oligomers consists in locking them into nontoxic structures such as fibrils. In the past few years, dendrimers ${ }^{4}$ have been shown to possess antiprionic ${ }^{5-8}$ and anti-A $\beta$ properties. $^{9-13}$ Maltose-modified PPI dendrimers are able to convert toxic $\mathrm{A} \beta$ oligomers into nontoxic $\mathrm{A} \beta$ glycofibrils in vitro. ${ }^{12}$ Fourth generation PPI maltose dendrimers can glue together $\mathrm{A} \beta(1-40)$ growing fibrils from small $\mathrm{A} \beta$ oligomers and those clumped glycofibrils become not toxic for cultured cells. ${ }^{12}$ It can be suggested that PPI maltose dendrimers bind to $\mathrm{A} \beta(1-40)$ and change the surface charge of amyloid fibrils thus reducing the interaction of $\mathrm{A} \beta(1-40)$ with cell membrane and then decreasing toxicity. Alternatively, $\mathrm{A} \beta(1-40)$ reduced toxicity in the presence of PPI maltose dendrimers might be related to the large size of clumped glycol-aggregates which make them unable to penetrate into the cells, thus, blocking putative intracellular $\mathrm{A} \beta$ toxicity. The effect of glycodendrimers upon the aggregation of $A \beta(1-40)$ is similar to the effect of poly(amido amine) (PAMAM) and phosphorus dendrimers on

Received: June 30, 2013

Revised: $\quad$ August 22, 2013

Published: September 4, 2013 
A

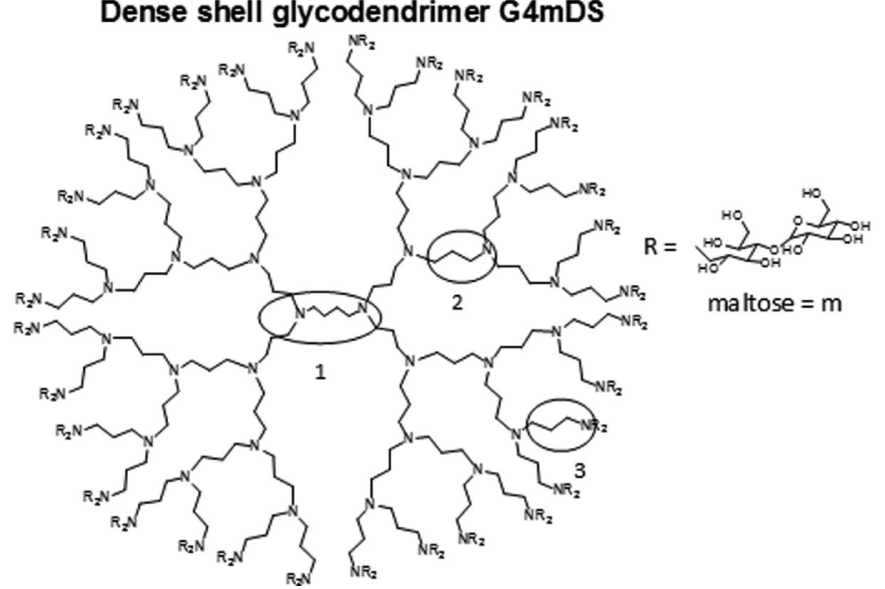

B

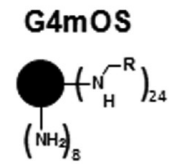
G4mDS

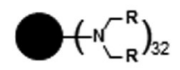
G5mDS

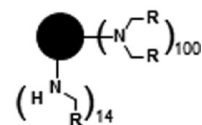<smiles>O=C(O)COC(=O)OC(O)O</smiles>

C

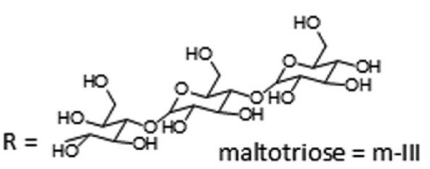

Figure 1. Structure of fourth (G4) and fifth (G5) generation PPI dendrimers possessing maltose (m) or maltotriose (m-III). (A) Simplified structure of the fourth generation poly(propylene imine) dendrimer with dense maltose shell, G4mDS. (1) poly(propylene imine) core; (2) branching point; (3) terminal amino group with two maltose substituents as R. (B) Main structural characteristics of terminal amino group in maltose shell dendrimers open shell (G4mOS) and dense shell (G4mDS and G4mDS). (C) Maltotriose open shell dendrimers (G4m-IIIOS).

$\mathrm{A} \beta(1-28)$ and PrP185-208. At low dendrimer-peptide ratios the number of fibrils grows, whereas the rate of amorphous aggregates accelerates as the dendrimer-peptide ratio is increased. $^{12,13}$

Dendrimers as antineurodegenerative agents, ${ }^{5-13}$ several drug delivery systems, ${ }^{14,15}$ and novel immunogens ${ }^{16}$ may have application in $\mathrm{AD}$ therapy although all of them need to overcome some adverse effects. Low-molecular weight compounds have also demonstrated their utility by reducing neurotoxic $\mathrm{A} \beta$ oligomers in vivo. ${ }^{17,18}$

Dendrimers are special classes of nanostructures that may be designed and regulated as a function of their size, shape, surface chemistry, and interior void space. They are of eminent interest in certain medical applications such as drug delivery, gene transfection, and imaging. ${ }^{19}$ Dendrimers consist of three major architectural components: a central core, a branching unit, and a terminal group. A typical composition of fourth generation PPI dendrimers can be seen in Figure 1A. Generally, each branching unit ends with a reactive terminal group in the outer sphere to which at least two new molecules are attached. The number of branches identifies the generation class of a particular dendrimer. Because of their exponential growth, higher generation dendrimers are as large as medium-size proteins. ${ }^{20}$ Molecules attached to the terminal reactive groups of the dendrimer determine its physical and chemical properties. ${ }^{21}$ Unmodified amino-terminated PAMAM, phosphorus, and PPI dendrimers are not ideal candidates in the field of biomedical applications due to their high toxicity. ${ }^{13}$ The toxicity of these dendrimers is mainly caused by strong electrostatic interactions between the positive charges on the dendrimer's surface and the negatively charged elements present on the surface of cell membranes. However, sugar decoration, besides other shell decoration of dendrimers, ${ }^{20}$ significantly improves the biocompatibility of PPI dendrimers. $^{12,22}$ Thus, maltose moieties on the dendrimer surface also provide good solubility under physiological conditions. ${ }^{21}$ Maltose PPI dendrimers are practically devoid of hemolytic activity in comparison with unmodified PPI dendrimers ${ }^{23,24}$ and show reduced toxicity in vitro ${ }^{12}$ and in vivo. ${ }^{22}$

To further investigate the suitability of dendrimers as antiamyloidogenic agents several aspects need to be assessed, including the effects of distinct sugar modifications of PPI dendrimers on $\mathrm{A} \beta$ aggregation, the nontoxic activity of the PPI maltose dendrimers, and the possibility of administration of PPI glycodendrimers in vivo. In this sense, the blood-brain barrier (BBB), composed principally of specialized capillary endothelial cells fitted with highly restrictive tight junctions, impedes the passage of many compounds to the central nervous system. ${ }^{25}$ Only a few dendritic therapeutic compounds can cross the $\mathrm{BBB}$, such as transferrin-conjugated PEG, modified PAMAM dendrimers, ${ }^{26}$ cetuximab-conjugated PAMAM dendrimers, ${ }^{27}$ and PPI G4m-IIIOS. ${ }^{28}$ Unfortunately, all of these dendrimers are characterized by the presence of a net surface charge that results in low biocompatibility.

In the present study, we tested fourth (G4) and fifth (G5) generations of PPI dendrimers decorated with maltose (m) or with maltotriose (m-III). Higher sugar surface density correlates with a higher density of hydrogen bonds $(\mathrm{OH}-$ $\mathrm{COOH}, \mathrm{OH}-\pi$, and $\mathrm{OH}-\mathrm{N}$-heterocycles, among others) between the PPI glycodendrimer and other biomolecules. ${ }^{12}$ PPI dendrimers possessing about $40 \%$ of terminal amino groups modified with sugar molecules are called "open sugar shell dendrimers" (OS), while PPI dendrimers possessing 90$100 \%$ of terminal amino groups modified with sugar molecules are described as "dense sugar shell dendrimers" (DS). G4mOS, G4m-IIIOS, G4mDS, and G5mDS are the main compounds assessed in this study. The hydrogen bond capacity gradually increases as follows: G4mOS < G4m-IIIOS < G4mDS < G5mDS. The simplified molecular structures and main characteristics of sugar-modified PPI dendrimers and their conjugates used in the present study are shown in Figure 1 and Table 1 .

Table 1. Molar Masses for Glycodendrimers Determined by ${ }^{1}$ H NMR Approach ${ }^{21}$ and Number of Attached Sugar Units (Maltose $=\mathrm{m}$; Maltotriose $=\mathrm{m}-\mathrm{III}$ ) in Glycodendrimers Used in This Study

$\begin{array}{lcc} & \text { mol mass }^{21}(\mathrm{~g} / \mathrm{mol}) & \text { sugar units attached } \\ \text { G4m-IIIOS } & 14730 & 23 \\ \text { G4mOS } & 11530 & 24 \\ \text { G4mDS } & 23400 & 64 \\ \text { G5mDS } & 44500 & 114\end{array}$


Dense maltose shell dendrimers (G4mDS and G5mDS) are considered as amphiphilic macromolecules possessing electroneutral shells. ${ }^{5}$ The interactions between these dendrimers and various biological systems are preferably governed by $\mathrm{H}$-bond active surfaces. ${ }^{21}$ In contrast, open sugar shell dendrimers (G4mOS and G4m-IIIOS) have residual positively charged amino groups, and the interaction between open sugar shell dendrimers and different biomolecules or bioactive molecules is also dependent on electrostatic interactions.

In the present study we assessed the effects of several sugar modifications of PPI dendrimers on the aggregation of the $\mathrm{A} \beta(1-40)$ and their capacity to reduce the toxicity of the $\mathrm{A} \beta(1-42)$ peptide and natural $\mathrm{A} \beta$ contained in $\mathrm{AD}$ brain homogenates on cultured cells. Then, we tested the ability of PPI maltose dendrimers to cross the BBB. Finally, we explored the effects of G4mOS and G4mDS on $\mathrm{A} \beta$ aggregation and cognitive performance in APP/PS1 transgenic mice as a model of cerebral $\beta$-amyloidosis with similarities to familial $\mathrm{AD}$, to gain understanding of the potential therapeutic benefits of G4mOS and G4mDS.

\section{MATERIALS AND METHODS}

Reagents. Poly(propylene imine) (PPI) dendrimers of the fourth and fifth generation were supplied by SyMO-Chem (Eindhoven, The Netherlands). Maltose monohydrate, maltotriose, sodium borate, boran pyridine complex, and fluorescein-5/6-isothiocyanate (FITC) were purchased from Sigma-Aldrich (Germany). PPI dendrimers modified with maltose and maltotriose were synthesized and characterized as previously described. ${ }^{21,29}$ Conversion of the maltose-modified PPI dendrimer with FITC was used for the detection and mapping of labeled dendrimers in cells and brain tissue. Synthesis of FITC-labeled maltose-modified PPI dendrimer was done as described. ${ }^{28}$ Table 1 summarizes the molecule masses of glycodendrimers used in the present study.

A $\beta(1-40)$ [DAEFRHDSGYEVHHQKLVFFAEDVGSNKGAIIGLMVGGVV] and A $\beta(1-42)$ [DAEFRHDSGYEVHHQKLVFFAEDVGSNKGAIIGLMVGGVVIA] were obtained from JPT Peptide Technologies GmbH (Germany). A $\beta$ stock solutions were prepared according to established protocol. ${ }^{30}$ Amyloid peptides were dissolved in $10 \mathrm{mM}$ HEPES buffer (Sigma-Aldrich, Madrid, Spain) with $0.02 \% \mathrm{NH}_{3}$ at $\mathrm{pH} 12$; stock concentration was $250 \mu \mathrm{M}$, and aliquots were kept at $-80{ }^{\circ} \mathrm{C}$ until use.

Synchrotron Small Angle X-ray Scattering (SAXS). A series of SAXS measurements of $5 \mathrm{mM}$ solutions of PPI glycodendrimers were carried out at EMBL Beamline X3331 (DESY, Hamburg, Germany). The scattering pattern was measured on a pilatus $1 \mathrm{M}$ detector (Dectris, Villingen, Switzerland) using a sample-detector distance of $2.7 \mathrm{~m}$ and a wavelength of $\lambda=0.15 \mathrm{~nm}$. The concentration of each sample was $1.2 \mathrm{mg} / \mathrm{mL}$ in phosphate buffered saline. To monitor for radiation damage, $8 \times 15 \mathrm{~s}$ exposures were collected for each sample; no radiation damage was observed. Measurements were performed at $37^{\circ} \mathrm{C}$; scattering vectors $0.05<s<5.0 \mathrm{~nm}^{-1}(s=4 \pi \sin \theta / \lambda)$ were collected. All data sets were normalized to the incident beam intensity and corrected for the detector response. Scattering of the buffer was subtracted using the computer program PRIMUS, ${ }^{32}$ and distance distribution functions were obtained using the program GNOM. ${ }^{32} \mathrm{Ab}$ initio shape determination was simulated using a single phase dummy atom model DAMMIN. ${ }^{33}$

Fluorescence Measurements. Thioflavin T (ThT; SigmaAldrich, Spain) fluorescence variations were measured during $\mathrm{A} \beta(1-$ 40) aggregation as described. ${ }^{30}$ The aggregation process was initiated by adding an aliquot of the peptide stock solution into $1 \mathrm{~mL}$ fluorescence cuvette containing $60 \mathrm{mM}$ HEPES buffer at $\mathrm{pH}$ 7.2. The concentration $\mathrm{A} \beta(1-40)$ for all fluorescent measurements was $25 \mu \mathrm{M}$, the temperature was $37{ }^{\circ} \mathrm{C}$, and the $\mathrm{pH}$ 7.4. Dendrimers were added into the cuvette before peptide addition. Excitation and emission wavelengths were set at 450 and $490 \mathrm{~nm}$, respectively, and the temperature was $37^{\circ} \mathrm{C}$.

Transmission Electron Microscopy. A total of $10 \mu \mathrm{L}$ of sample was placed on a carbon-coated copper grid for $10 \mathrm{~min}$ and dried with Whatman tissue. The sample was stained with $2 \%(\mathrm{w} / \mathrm{v})$ uranyl acetate for $30 \mathrm{~s}$ and dried with Whatman. Electronic micrographs were obtained using a Hitachi H-7000 electron microscope.

Preparation of Human Brain Tissue Extracts. Human brain tissue was obtained from the Brain Bank of the Institute of Neuropathology (HUB-ICO-IDIBELL Biobank). Fresh samples of the parietal cortex $(n=3 \mathrm{AD}$ Braak and Braak stages V/VI, and $n=3$ age-matched controls) were obtained at the time of the autopsy (postmortem delay less than $6 \mathrm{~h}$ ), and immediately frozen and stored at -80 ${ }^{\circ} \mathrm{C}$ until use (Table 2). Frozen brain tissues were homogenized in 4

\section{Table 2. Autopsy and Clinical Data}

\begin{tabular}{cccl} 
autopsy & PM delay $(\mathrm{h} / \mathrm{min})$ & gender/age & \multicolumn{1}{c}{ diagnosis } \\
1 & $3 / 00$ & $\mathrm{M} / 93$ & $\mathrm{AD}$, Braak Stage V \\
2 & $5 / 15$ & $\mathrm{~F} / 81$ & $\mathrm{AD}$, Braak Stage V \\
3 & $7 / 00$ & $\mathrm{~F} / 56$ & $\mathrm{AD}$, Braak Stage VI \\
4 & $3 / 30$ & $\mathrm{M} / 64$ & $\mathrm{NL}$ (no lesions) \\
5 & $6 / 45$ & $\mathrm{~F} / 54$ & $\mathrm{NL}$ (no lesions) \\
6 & $5 / 20$ & $\mathrm{M} / 57$ & $\mathrm{NL}$ (no lesions)
\end{tabular}

volumes (wt/vol) of TBS extraction buffer $[140 \mathrm{mM} \mathrm{NaCl}, 3 \mathrm{mM}$ $\mathrm{KCl}, 25 \mathrm{mM}$ Tris, $\mathrm{pH} 7.4,5 \mathrm{mM}$ EDTA, and protease inhibitor cocktail (Roche, Madrid, Spain)]. Homogenates were spun at $100000 \mathrm{~g}$ for $1 \mathrm{~h}$, and the supernatants were saved as the brain soluble fractions. $\mathrm{A} \beta(1-40)$ and $\mathrm{A} \beta(1-42)$ human ELISA kits (Invitrogen Corporation, Camarillo, CA, U.S.A.) were used to quantify the levels of $A \beta(1-40)$ and $A \beta(1-42)$ in brain soluble fractions. Quantitative determination was carried out according to the instructions of the supplier.

Cell Culture. Human neuroblastoma cell line SH-SY5Y was purchased from the European Collection of Cell Cultures (ECACC). Cells were grown in Dulbecco's modified Eagle's medium/Nutrient Mixture F-12 Ham with L-glutamine, (PAA,Cell Culture, U.K.), supplemented with $1 \%$ nonessential amino acids (PAA), 100 units $/ \mathrm{mL}$ penicillin, $100 \mu \mathrm{g} / \mathrm{mL}$ streptomycin, and $10 \%$ fetal bovine serum (FBS). Cells were maintained at $37{ }^{\circ} \mathrm{C}$ in a humidified atmosphere containing $5 \% \mathrm{CO}_{2}$.

Cell Viability Assay. TMT (3-[4,5-dimethylthiazol-2-yl]-2,5diphenyl tetrazolium bromide; Sigma-Aldrich) assay was selected for screening cytotoxicity. SH-SY5Y cells were plated at a density of $2 \times$ $10^{4}$ cells $/ \mathrm{cm}^{2}$ in 96-well culture dishes. After $24 \mathrm{~h}, 10 \%$ FBS medium was replaced by $1 \% \mathrm{FBS}$. A total of $24 \mathrm{~h}$ later, cells were treated with test materials, followed by cell washing with PBS, and incubation with MTT $(0.5 \mathrm{mg} / \mathrm{mL}$ in phenol red-free DMEM (Sigma-Aldrich) medium) for $1 \mathrm{~h}$ at $37^{\circ} \mathrm{C}$. Formazan crystals were dissolved by adding v/v dimethyl sulfoxide (DMSO, Sigma-Aldrich). Plates were covered with by aluminum foil and placed on a rotating platform for 5 $\min$ at $100 \mathrm{rpm}$. The absorbance was measured with a spectrophotometer at a wavelength of $570 \mathrm{~nm}$ using a Victor's ${ }^{3}$ plate reader (Parkin-Elmer, Madrid, Spain).

To study the effect of PPI glycodendrimers on $\mathrm{A} \beta(1-42)$ toxicity, $0.1 \mu \mathrm{M}$ PPI glycodendrimers were tested in culture cells treated with 1 $\mu \mathrm{M} \mathrm{A} \beta(1-42) . \mathrm{A} \beta(1-42)$ and dendrimers were added to cell culture and incubated $24 \mathrm{~h}$ before MTT assays. $0.1 \mathrm{mM}$ stock solutions of PPI glycodendrimers were prepared in PBS, and $\mathrm{A} \beta(1-42)$ stock solution was prepared as described above; all solutions were filter-sterilized with a $0.22 \mu \mathrm{m}$ nylon syringe filter (Merck Millipore, Spain). Cell viability of untreated SH-SYSY cells was taken as $100 \%$ viability, whereas viability of cells treated with $1 \mu \mathrm{M} \mathrm{A} \beta(1-42)$ without PPI glycodendrimers was used as a control of $\mathrm{A} \beta(1-42)$-induced cytotoxicity.

To study the effect of PPI glycodendrimers on AD brain extract toxicity, $0.01 \mu \mathrm{M}$ PPI glycodendrimers were added to $25 \mu \mathrm{g}$ of brain tissue extracts and the final volume was adjusted to $20 \mu \mathrm{L}$ with PBS. The mixture of brain extracts and PPI glycodendrimers was incubated 
at $37^{\circ} \mathrm{C}$ for $3 \mathrm{~h}$ by shaking at $230 \mathrm{rpm}$. The reaction was stopped by freezing. Cells were treated with tissue extracts alone or with a mixture of tissue extracts and dendrimers for $72 \mathrm{~h}$ before MTT assays. Viability of cells treated with $\mathrm{AD}$ brain extract without dendrimers was used as a control of $\mathrm{AD}$ brain tissue-induced toxicity. Viability of cells treated with extracts of control brain tissues preincubated with PPI glycodendrimers was used to monitor possible side-effects of dendrimers related to nonspecific binding. As before, cell viability of untreated SH-SY5Y cells was taken as $100 \%$ viability. The final volume of medium was always $0.2 \mathrm{~mL}$ per well.

Detection of FITC-PPI Maltose Dendrimers in SH-SY5Y Cells. For the study of cellular uptake of FITC-G4mDS, FITCG5mDS, and FITC-G4mOS dendrimers, SH-SY5Y cells were incubated with $10 \mu \mathrm{M}$ maltose dendrimers for $24 \mathrm{~h}$. Cells were fixed with 4\% PFA after two 5 min PBS washes. All samples, including the control, were incubated with anti-FITC primary antibody against FITC-labeled dendrimers as described below and examined with Nikon fluorescence microscope.

Synchrotron X-ray Microscopy. SH-SY5Y cells were grown on the surface of HZBII Au gold microscope grids (Gilder Grids, U.K.) under serum deprivation and treated with $10 \mu \mathrm{M}$ FITC-G4mDS and FITC-G5mDS for $24 \mathrm{~h}$. Then the cells were washed with PBS and immediately frozen at $-150{ }^{\circ} \mathrm{C}$ in liquid ethane using CryoplungeTM3 (Gatan, Germany). Frozen grids were transferred to the HZB X-ray microscope beamline U41 at the BESSY II electron storage ring (Berlin, Germany) at $-196{ }^{\circ} \mathrm{C}$ in liquid nitrogen. We used cryogenic conditions and photon energy (i.e., $510 \mathrm{eV}$ ) within the water window to take advantage of the high natural contrast of biological material to acquire X-ray data sets as described. ${ }^{34}$ Regions of major interest with appropriate characteristic and thickness for tilted series acquisition were selected at magnification $M=1300$. The images were collected using an objective zone plate with an outermost zone width of $40 \mathrm{~nm}$ to maintain the cell cytoplasm in focus, resulting in a spatial resolution of about $60 \mathrm{~nm}$.

Animals. The experiments were carried out on male APP/PS1 mice ${ }^{35}$ and wild-type littermates aged five months (early symptomatic stage) following the guidelines of the local ethics committee. The animals were maintained in $12 \mathrm{~h}$ light/dark cycles in a temperatureregulated animal facility with free access to water and food.

Experimental Design. Three experimental treatment settings were designed, covering intraperitoneal (i.p.) administration, shortterm intranasal (i.n.) administration, and long-term intranasal administration.

1. The study of i.p. administration was carried out in nontransgenic littermates aged 6 months treated with FITCG4mDS, FITC-G5mDS dendrimers or with PBS $(n=3), 10$ $\mathrm{mg} / \mathrm{kg} / \mathrm{bw} /$ day. After 10 days of treatment, the animals were killed, and their brains and livers were dissected on ice, immediately frozen, and stored at $-80{ }^{\circ} \mathrm{C}$ until use.

2. The study of short-term i.n. administration was also conducted in nontransgenic littermates aged 6 months treated with FITC-G4mDS, FITC-G4mOS, FITC-G5mDS, or the PBS $(n=3)$ by applying two equal drops with a micropipet to each nasal cavity $(5 \mu \mathrm{L})$, resulting in a total dose of $10 \mathrm{mg} / \mathrm{kg} / \mathrm{bw} /$ day for 5 days. After this time, the animals were perfused through the left cardiac ventricle with cold $10 \mathrm{mmol} / \mathrm{L} \mathrm{PBS} \mathrm{pH}$ 7.4 under deep whole-body anesthesia (ketamine/xylazine, 5:1; $0.10 \mathrm{~mL} / 10 \mathrm{~g} / \mathrm{bw}$, i.p.). The brain was rapidly removed from the skull, dissected, and frozen and stored at $-80^{\circ} \mathrm{C}$ until use.

3. The study of long-term i.n. administration lasted one month and was done in APP/PS1 and wild-type (WT) nontransgenic littermates. At the age of 5 months, APP/PS1 and WT mice were randomly divided into three experimental groups as follows: six transgenic and six WT mice received $0.1 \mathrm{mg} / \mathrm{kg} /$ bw/day G4mOS; five transgenic and six WT mice received 1 $\mathrm{mg} / \mathrm{kg} / \mathrm{bw} /$ day G4mDS; finally, five transgenic and five WT mice received the same volume of PBS $(5 \mu \mathrm{L})$. At the end of long-term i.n. treatment, memory evaluation tests were performed. This paradigm was performed as described ${ }^{35}$ in a V-maze (Panlab, Barcelona, Spain). Briefly, on the first day, mice were habituated by allowing them to freely explore the $\mathrm{V}$ maze apparatus. On the second day, mice were placed for the same length of time in the same V-maze where two identical objects were situated at the ends of the arms. Then, $24 \mathrm{~h}$ after the training session, the animals were placed in the V-maze where one of the two familiar objects was replaced by a novel object. The time that the animals spent exploring the two objects was recorded and the "object recognition index" was calculated considering the difference between the time spent exploring the novel and the familiar objects divided by the total time spent exploring the two objects. Animals suffering from memory impairment revealed a lower object recognition index when compared with that exhibited by normal mice. ${ }^{35}$

After memory tests, the animals were killed under deep anesthesia and the brain was rapidly removed from the skull. The right hemisphere was immediately frozen and stored at $-80{ }^{\circ} \mathrm{C}$ until use, while the left hemisphere was fixed in $4 \%$ buffered paraformaldehyde.

$\mathrm{A} \beta(1-40)$ and $\mathrm{A} \beta(1-42)$ quantitative determination of animals after long-term i.n. treatment and 6 transgenic mice at the age of 5 months were prepared according to the protocol described above.

Fluorescent measurements of mouse brain tissue extract: This was performed as described ${ }^{28}$ with minor modifications. Briefly, the frozen hemisphere was put in 2 volumes of ice-cold PBS and homogenized with a motorized rotor; $50 \%$ tricholoracetic acid in $5 \times$ vol was added to precipitate proteins. The tissue homogenates were centrifuged for $20 \mathrm{~min}$ at $500 \mathrm{~g}$ in $4{ }^{\circ} \mathrm{C}$, and the $\mathrm{pH}$ of homogenate suspensions was adjusted to $\mathrm{pH} 7.4$ with $10 \mathrm{M} \mathrm{NaOH}$. Immediately after preparation of tissue extracts, the fluorescence of FITC labeled dendrimers was recorded at $485 \mathrm{~nm}$ excitation and $500-700 \mathrm{~nm}$ emission wavelength. The content of FITC-labeled dendrimers was quantified with linear standard curves of FITC-labeled dendrimers and expressed per gram of tissue once subtracted autofluorescent background.

Immunohistochemistry and Thioflavin S Staining. Frozen sections $15 \mu \mathrm{m}$ thick were obtained with a cryostat and mounted onto slides and fixed in $4 \%$ paraformaldehyde for $10 \mathrm{~min}$. Sections were incubated with $0.1 \%$ TX-100 and $10 \%$ normal goat serum for $60 \mathrm{~min}$ at room temperature. Sections containing FITC-labeled dendrimers were then incubated overnight at $4{ }^{\circ} \mathrm{C}$ with anti-FITC primary antibody (1:200; BIORBYT, U.K.), incubated for $1 \mathrm{~h}$ at room temperature with Alexa Fluor 488 goat antirabbit antibody (1:400; Molecular Probes, Eugene, OR, U.S.A.), washed, mounted with Immuno-Fluore Mounting medium (ICN Biomedicals, CA, U.S.A.), and examined with a Nikon fluorescence microscope.

Paraffin-embedded brains were cut into $4 \mu \mathrm{m}$ sections and placed on glass slides. Sections for $\mathrm{A} \beta$ immunohistochemistry were treated as described. ${ }^{35}$ For ThS staining, dewaxed sections were treated with a saturated solution of Sudan Black B (Merck, Darmstadt, Germany) for 10 min to block the autofluorescence of lipofuscin granules present in cell bodies, and then rinsed in $70 \%$ ethanol and washed in distilled water. Sections were incubated with $1 \%$ Thioflavin S (ThS; Sigma, St. Louis, $\mathrm{MO}$ ) in $70 \%$ ethanol for $10 \mathrm{~min}$, rinsed in $70 \%$ ethanol, and washed in $\mathrm{H}_{2} \mathrm{O}$. Slides were mounted with Immuno-Fluore Mounting medium (ICN, Biomedicals) and sealed for fluorescence microscope observation. ThS staining was visualized using a specific filter set (excitation: $405-445 \mathrm{~nm}$; emission: $515-565 \mathrm{~nm}$ ). The A $\beta$ burden was quantified using Adobe Photoshop CS4 software (Adobe Systems, San Jose, CA, U.S.A.).

Synchrotron FTIR Mapping of Mouse Brain Tissue and Data Analysis. Coronal frozen brain sections, $10 \mu \mathrm{m}$ thick, were obtained with a cryostat, mounted onto $\mathrm{CaF}_{2}$ slides (Crystran, U.K.), and then fixed in $4 \%$ paraformaldehyde for $10 \mathrm{~min}$. FTIR measurements were carried out at the FTIR spectromicroscopy beamstation of ID21 (ESRF, Grenoble, France). Amyloid plaques were first detected in UV mode followed by collection of FTIR spectromicroscopic maps in reflection mode using an infrared microscope (Thermo Nicolet Nexus) coupled to an FTIR spectrometer (Thermo Nicolet Continuum). Maps were collected with an $8 \times 8 \mu \mathrm{m}^{2}$ FTIR beam, step size $6 \mu \mathrm{m}$, with 64 scans of each pixel. Spectra were acquired over the $700-4000 \mathrm{~cm}^{-1}$ region using the MCT-B detector. Maps were analyzed with OMNIC/Atl $\mu$ s software (Thermo Nicolet), on original 

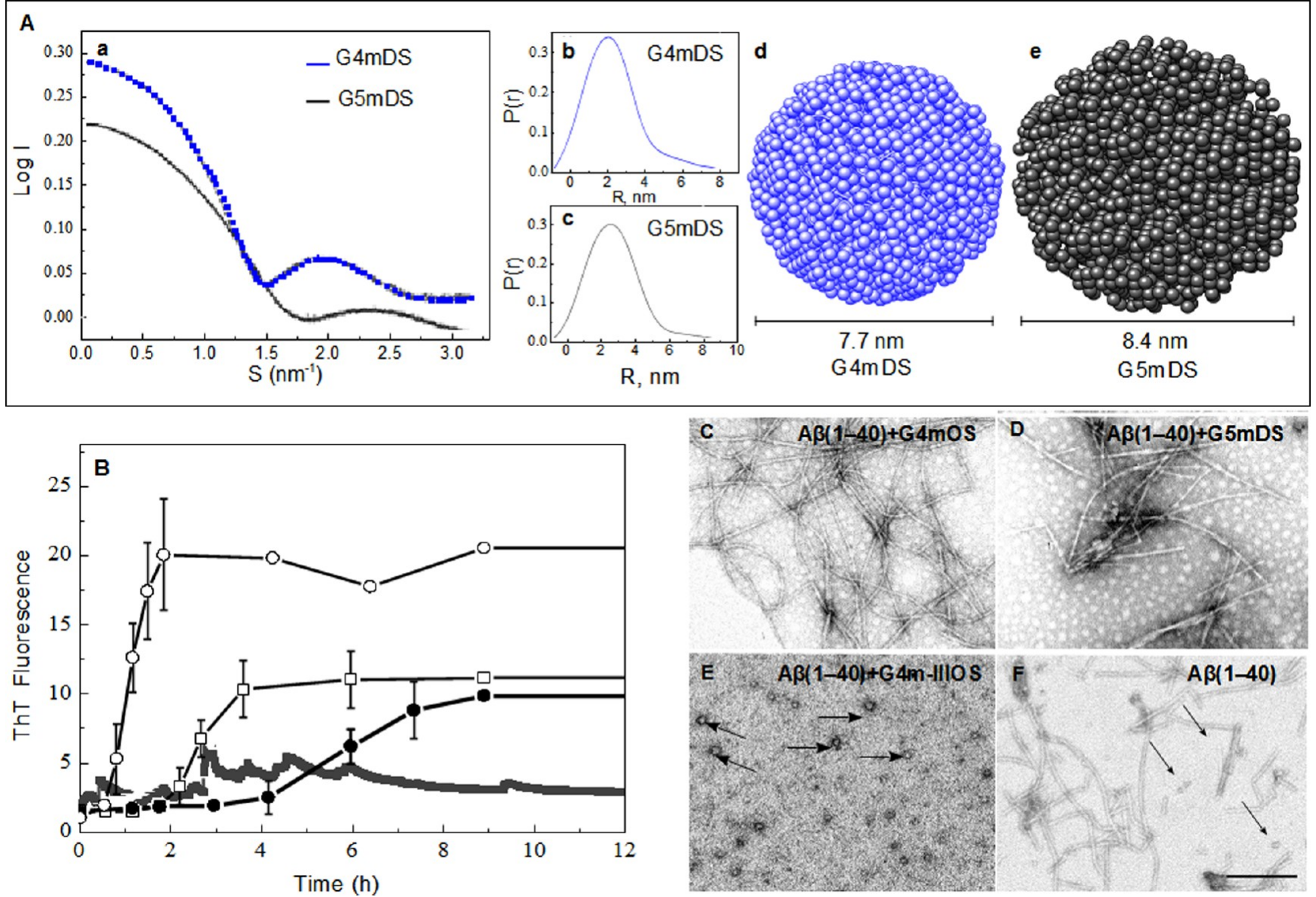

Figure 2. Size and shape of PPI-maltose dendrimers and their effect on $A \beta(1-40)$ aggregation. (A) SAXS patterns of fourth and fifth generation of PPI maltose dendrimers in PBS at $37^{\circ} \mathrm{C}$ (a); Distance distribution functions $p(r)$ calculated for G4mDS (b) and G5mDS(c); DAMMIF ab initio models illustrate the shapes of solutes (d, e). (B) Aggregation of synthetic A $\beta(1-40)$ in the presence of glycodendrimers measured by ThT fluorescence variation. $(\bullet)$ A $\beta(1-40)$ aggregation in the absence of glycodendrimers; $(O)$ G4mOS accelerates A $\beta(1-40)$ formation of ThT positive structures (e.g., fibrils) at the dendrimer-peptide ratio 0.01 to $1 ;(\square) \mathrm{G} 5 \mathrm{mDS}$ accelerates $\mathrm{A} \beta(1-40)$ fibril formation at the dendrimer-peptide ratio 0.005 to 1; Gray line indicates that G4m-IIIOS inhibits $\mathrm{A} \beta(1-40)$ fibril formation at the ratio to peptide of 0.01 to 1 . No significant differences were found with respect to the final values shown in the figure after 24 and $48 \mathrm{~h}$. Data are expressed as mean values $\pm \mathrm{SD}, n=3$. Transmission electron microscopy (TEM): (C) Only fibrils of A $\beta(1-40)$ were found after $24 \mathrm{~h}$ of incubation in the presence of G4mOS (ratio 0.01 to 1$)$ and (D) G5mDS (ratio 0.005 to 1). The holes in carbon coating of TEM grids are seen as white spots on images D and E. (E) A $\beta(1-40)$ plus G4m-IIIOS produces granular aggregates (arrows). (F) Coexistence of fibrils and small aggregates (arrows) of $A \beta(1-40)$ in the absence of dendrimers. Bar $=$ $100 \mathrm{~nm}$.

unprocessed spectra. Aggregated protein was detected by measuring the absorbance ratio $A_{1630-1620} / A_{1662-1652} \mathrm{~cm}^{-1}$. 36

Gel Electrophoresis and Western Blotting. Equal amounts of soluble $\mathrm{A} \beta$ of mouse brain (10 ng per lane) were separated by native PAGE (4-15\%) before electrophoretic transfer onto nitrocellulose membranes (Bio-Rad, Spain). Membranes were blocked for $1 \mathrm{~h}$ at room temperature in Tris-buffered saline $(100 \mathrm{mM} \mathrm{NaCl}, 10 \mathrm{mM}$ Tris, $\mathrm{pH}$ 7.4) with $0.1 \%$ Tween 20 (TTBS) and 5\% nonfat milk. Immediately afterward, the membranes were incubated overnight with the monoclonal mouse anti-A $\beta(1-16) 6 \mathrm{E} 10$ antibody (1:1000; Covance, Spain) in TTBS with 5\% nonfat milk. Then, the membranes were incubated for $1 \mathrm{~h}$ at room temperature with a horseradish peroxidase-conjugated antimouse (1:2000; Sigma-Aldrich). Bands were visualized with chemiluminescence detection (Amersham ECL Prime Western Blotting Detection Reagent, GE Healthcare, U.K.).

\section{STATISTICAL ANALYSIS}

Experimental data were analyzed with one-way ANOVA followed by Tukey's post hoc test. Results of memory tests were analyzed with two-way ANOVA followed by Tukey's post hoc test. In all the experiments, the significance level was set at $p<0.05$.

\section{RESULTS}

In Vitro Effects of PPI Glycodendrimers. Dendrimer Shape and Size in Physiological Conditions. DAMIFF, a method to restore ab initio low resolution shape of molecules in solution from its SAXS pattern (Figure 2A, a-c), showed that, in PBS pH 7.4 at $37{ }^{\circ} \mathrm{C}$, PPI maltose dendrimers had spherical macromolecules with a diameter of $7.7 \mathrm{~nm}$ for G4 and $8.4 \mathrm{~nm}$ for G5 of maltose-modified PPI dendrimers (Figure 2A, $\mathrm{d}$ and e). The obtained results show that diameters for G4 and G5 of PPI maltose dendrimers in physiological conditions (PBS solution, $37^{\circ} \mathrm{C}$ ) are $10 \%$ larger than previously measured using a dynamic light scattering method at room temperature. ${ }^{21}$

Effect on $A \beta(1-40)$ Aggregation. In peptide stock solutions at $\mathrm{pH} 12, \mathrm{~A} \beta(1-40)$ peptide is present as a mixture of monomers and low molecular weight oligomers. When the $\mathrm{pH}$ is lowered to 7.4 , the $\mathrm{A} \beta(1-40)$ nucleation-dependent polymerization process is triggered. ${ }^{30}$ Because aggregation of 

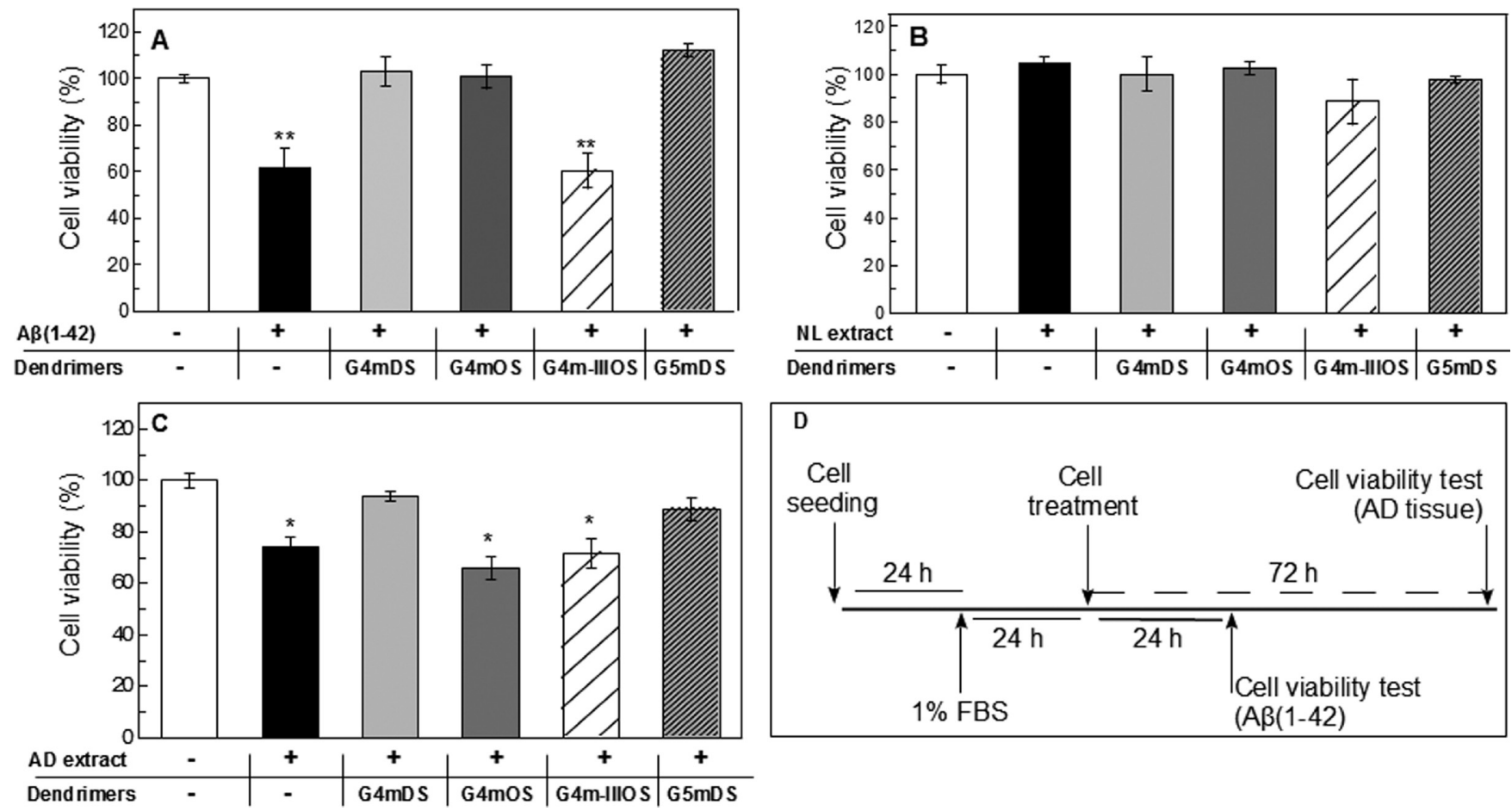

Figure 3. Effect of PPI glycodendrimers on $\mathrm{A} \beta(1-42)$ and $\mathrm{AD}$ brain extract toxicity on SH-SY5Y neuroblastoma cells. White columns correspond to control SH-SY5Y cells grown in the absence of dendrimers, $\mathrm{A} \beta(1-42)$ or brain tissue extracts. These values are taken as $100 \%$ of cell viability in all experiments. (A) MTT assay of $\mathrm{A} \beta(1-42)$ toxicity in the absence (black column) and the presence of glycodendrimers. A reduction in cell viability occurs after $24 \mathrm{~h}$ of incubation with $1 \mu \mathrm{M} \mathrm{A} \beta(1-42)$. Addition of $0.1 \mu \mathrm{M}$ of maltose-modified PPI dendrimers reduces the toxicity of $\mathrm{A} \beta(1-$ 42), whereas the addition $0.1 \mu \mathrm{M}$ maltotriose-modified PPI dendrimers does not. (B) Brain tissue with no lesion (NL) in the presence of $0.01 \mu \mathrm{M}$ PPI glycodendrimers is not toxic to the SH-SY5Y cultures. (C) AD brain tissue toxicity in the presence of $0.01 \mu \mathrm{M}$ PPI glycodendrimers. Black column shows the reduction in cell viability after incubation with $\mathrm{AD}$ brain tissue extract alone. Increased cell viability was seen after adding $\mathrm{G} 4 \mathrm{mDS}$ or G5mDS, but not G4m-IIIOS or G5mDS. Statistics: one-way ANOVA followed by Tukey's post hoc test compared to SH-SY5Y untreated cells $(* p<0.05, * * p<0.01$, data are expressed as a mean \pm SEM, $n=3)$. Dendrimers have no effect on cultures exposed to NL brain tissue. (D) Sequence of events in cell cultures.

$\mathrm{A} \beta(1-42)$ is more rapid than that of $\mathrm{A} \beta(1-40)^{37}$ with a short nucleation phase that is difficult to monitor, $\mathrm{A} \beta(1-40)$ and not $\mathrm{A} \beta(1-42)$ was used for aggregation kinetics in the present study. We tested several concentrations of PPI glycodendrimers on aggregation of $\mathrm{A} \beta(1-40)$. The obtained results show that G4mOS and G5mDS favored $\mathrm{A} \beta(1-40)$ fibril formation at the dendrimer-peptide ratios 0.01:1 and 0.005:1 (Figure 2B). Higher concentrations of these dendrimers led to inhibition of fibril formation as has been reported for $\mathrm{G} 5 \mathrm{mDS}{ }^{12}$ data for G4mOS are not shown. TEM analysis confirmed the fibrillar morphology of $\mathrm{A} \beta(1-40)$ in the presence of $\mathrm{G} 4 \mathrm{mOS}$ and G5mDS, whereas no oligomers were detected (Figure 2C,D). G4m-IIIOS dendrimers inhibited $A \beta(1-40)$ fibril formation, resulting in the formation of non-ThT positive granular aggregates (Figure $2 \mathrm{E}$ ). Absence of glycodendrimers resulted in the coexistence of fibrils and small aggregates of $\mathrm{A} \beta(1-40)$ (Figure 2F).

Effect on $A \beta(1-42)$ Toxicity. A total of $1 \mu \mathrm{M} \mathrm{A} \beta(1-42)$ alone reduced $\mathrm{SH}-\mathrm{SY} 5 \mathrm{Y}$ cell viability to around $35 \%$ compared with untreated control SH-SY5Y cells. The $0.1 \mu \mathrm{M}$ maltosemodified PPI dendrimers G4mOS, G4mDS, and G5mDS completely reduced the toxicity of $\mathrm{A} \beta(1-42) 0.1 \mu \mathrm{M}$, but maltotriose-modified dendrimers G4m-IIIOS did not (Figure $3 A)$. Additionally, several concentrations of G4m-IIIOS against $\mathrm{A} \beta(1-42)$ toxicity were tested, and no antiamyloidogenic effect was found (data not shown).
Effect on Toxicity of AD Brain Tissue Extracts. TBS soluble extracts of brain tissue without lesions were not toxic for $\mathrm{SH}-$ SY5Y cells, alone or preincubated with any of the selected glycodendrimers (Figure 3B). After $72 \mathrm{~h}$ of incubation, AD brain tissue caused a $25 \%$ decrease in the viability of SH-SY5Y cells. This toxicity was blocked by preincubating $\mathrm{AD}$ brain tissue extracts with $0.01 \mu \mathrm{M}$ G4mDS and G5mDS. Interestingly, G4mOS or G4m-IIIOS did not reduce $\mathrm{AD}$ brain extract toxicity (Figure $3 \mathrm{C}$ ). Quantification of soluble $\mathrm{A} \beta(1-40)$ and $\mathrm{A} \beta(1-42)$ in $\mathrm{AD}$ brain tissue extracts, as assessed by ELISA, showed that the concentration range was higher for G4mDS than for G5mDS and that the antitoxic effect of dendrimers was optimal when the ratio of total soluble amyloid peptide to dendrimers was 1 to $10 \div 10^{3}$ for G4mDS, and 1 to $10 \div 10^{2}$ for G5mDS. The high ratios of dendrimers required to block the toxicity of $\mathrm{AD}$ brain tissue can be explained by nonspecific binding of dendrimers with some other brain tissue proteins.

Cellular Uptake of Glycodendrimers. Figure 4A-D shows representative fluorescent microscopy images, confirming that dendrimers crossed the cell membrane. Cryo X-ray microscopy detected the presence of high electron density formations in the cytoplasm of SH-SY5Y cells in the presence of glycodendrimers (Figure 4G,H). No fluorescence or similar electrondense structures were observed in the cytoplasm of nontreated control cells (Figure 4E,F).

In Vivo Effects of PPI Glycodendrimers. I.P. Administration of Dense Shell Maltose Dendrimers. FITC-labeled 


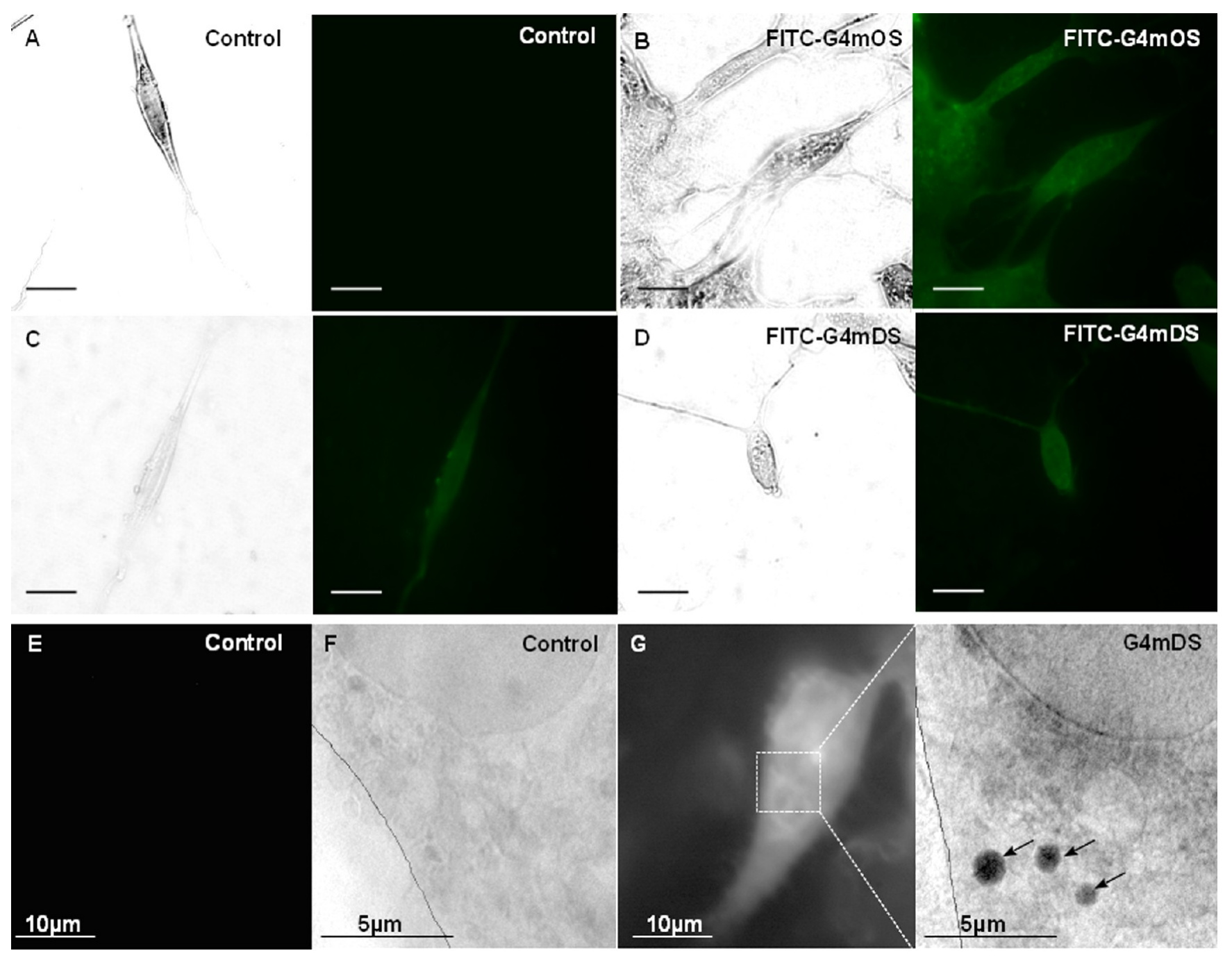

Figure 4. Detection of FITC-PPI maltose dendrimers in SH-SY5Y cells. Immunofluorescence microscopy, bright field and FITC immunofluorescence: (A) Control SH-SY5Y cell in the absence of dendrimers; (B, D) Cell uptake of FITC-G4mDS, FITC-G5mDS, and FITC-G4mOS. Cells were incubated with $10 \mu \mathrm{M}$ maltose dendrimers for $24 \mathrm{~h}$. After cell fixation, all samples including the control were incubated with anti-FITC primary antibody against FITC-labeled dendrimers. Scale bar $=20 \mu \mathrm{m}$. Synchrotron-based cryo-X-ray microscopy: (E) Control SHSY5Y cell under cryo fluorescent microscope (Zeiss (Germany), excitation $470 \mathrm{~nm}$, emission $525 \mathrm{~nm}$ ). (F) A part of the cytoplasm of a control SHSY5Y cell under cryo X-ray microscope. (G) SH-SY5Y cell treated with FITC-G4mDS under cryo fluorescent microscope. (H) A part of the same cell shown in (G) under cryo X-ray microscope. New electron-dense formations are marked with arrows. The outer cell membrane is shown by a line.

G4mDS and G5mDS dendrimers were i.p.-administered to sixmonth-old mice at a dose of $10 \mathrm{mg} / \mathrm{kg} / \mathrm{bw} /$ day for 10 days. All animals responded normally and showed $3 \%$ weight gain after treatment. Analysis of tissue homogenates by fluorescence spectroscopy showed an accumulation of FITC-labeled dendrimers in liver tissue but not in brain tissue (Figure 5A). Therefore, G4 and G5 maltose dense shell dendrimers with uncharged surface did not cross the BBB following i.p. administration.

I.N. Administration of Maltose Dendrimers. FITC-labeled G4mDS, G4mOS, and G5mDS were administered i.n. to sixmonth-old mice at a dose of $10 \mathrm{mg} / \mathrm{kg} / \mathrm{bw} /$ day for 5 days. All animals responded to the i.n. treatment normally with no visible signs of weakness or apathy. The spectra of FITC fluorescence showed a positive signal in brain tissue homogenates after i.n. treatment (Figure 5 B), thus, indicating that dense and open shell maltose PPI dendrimers had crossed the BBB. The efficiency was relatively low, as the amount of dense shell dendrimers in brain tissue did not exceed $6 \%$ of a single dose administered to the mouse. Yet open shell dendrimers were twice as successful as dense shell dendrimers in crossing the BBB.

Dense shell maltose PPI dendrimers did not accumulate in brain tissue. FITC-G5mDS given i.n. $(10 \mathrm{mg} / \mathrm{kg} / \mathrm{bw} / \mathrm{day})$ to nontransgenic littermates showed that the concentration of FITC-G5mDS in brain detected at the end of the treatment $(120 \mathrm{~h})$ was not significantly different with respect to the fluorescent signal in brain samples obtained after 24, 48, 72, and $96 \mathrm{~h}$ of treatment (Figure 5C). FITC-maltose dense shell PPI dendrimers after i.n. administration enter and spread into brain tissue, as is shown by immunofluorescence microscopy (Figure 5D).

Chronic I.N. Administration of Maltose Dendrimers to APP/PS1 Mice. APP/PS1 mice treated intranasally with $1 \mathrm{mg} /$ $\mathrm{kg} / \mathrm{bw} /$ day of G4mDS for 1 month showed no behavioral changes and reacted normally. However, APP/PS1 mice treated 

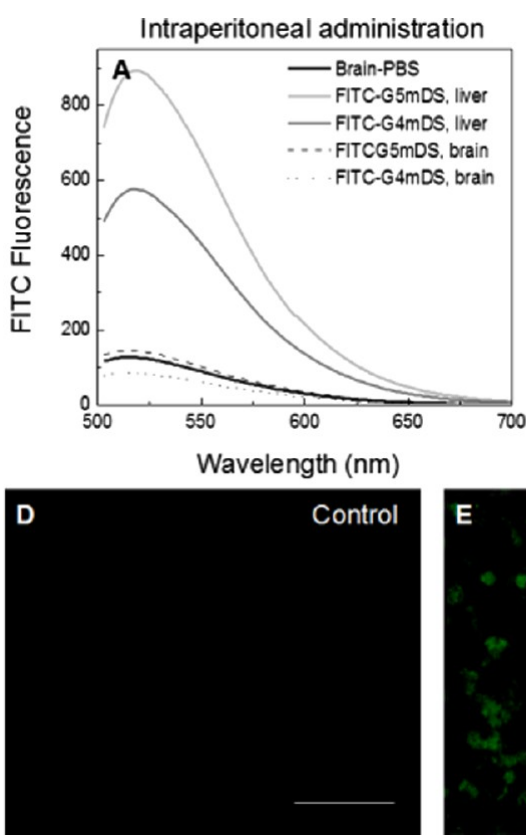
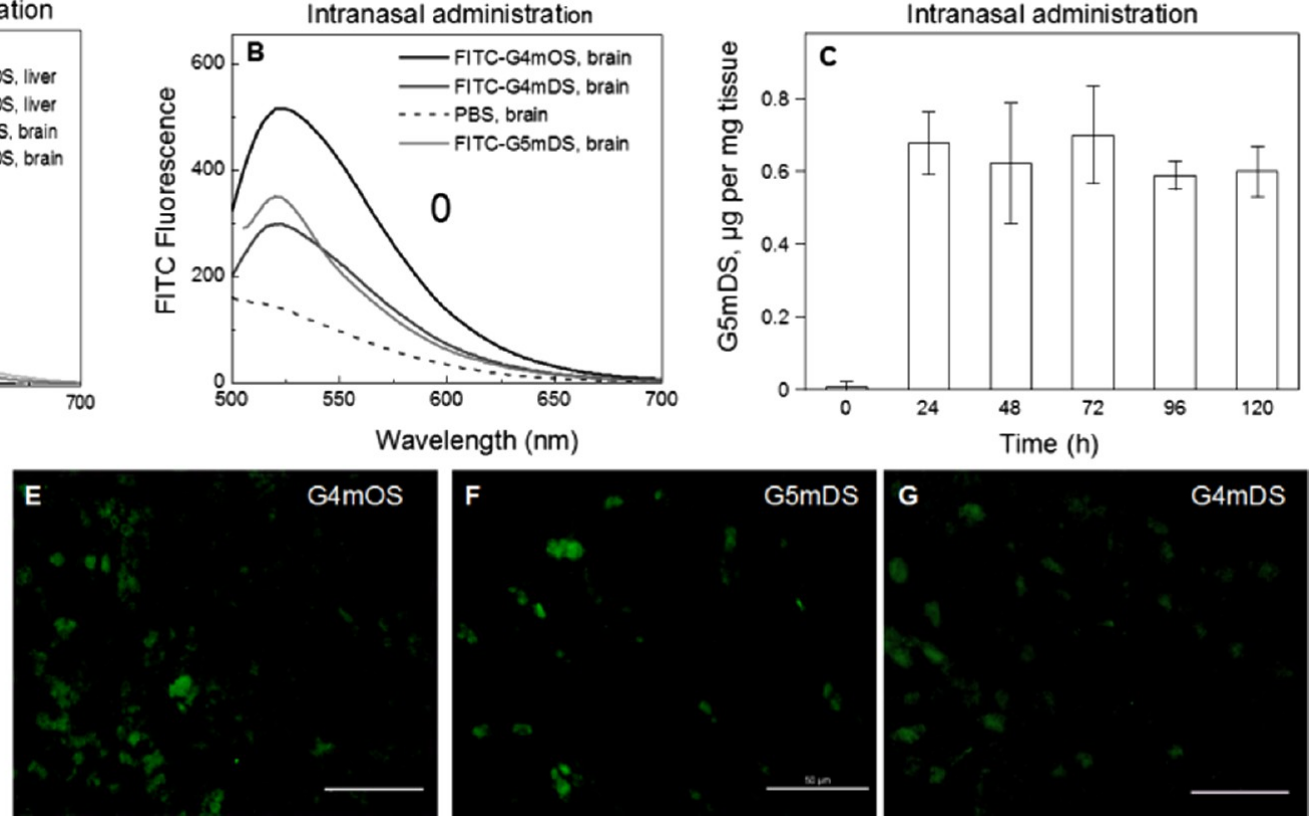

Figure 5. Glycodendrimers cross the BBB following i.n. administration. (A) FITC fluorescence spectra of liver and brain tissue homogenates after i.p. administration of FITC-G4mDS and FITC-G5mDS. (B) FITC fluorescence spectra of brain tissue homogenates after i.n. administration of FITC-G4mDS and FITC-G5mDS, demonstrating the presence of variable amounts of dendrimers in brain. (C) The dynamics of concentration of FITC-G5mDS (the largest dendrimer in the present study) in mouse brain tissue shows lack of accumulation of dendrimers over a period of 5 days $(24-120 \mathrm{~h}$ ) of i.n. administration (one-way ANOVA followed by Tukey's post hoc test $p>0.6$, data are expressed as a mean \pm SEM, $n=3$ ). (D-G) Immunofluorescence microscopy shows the presence of FITC-G4mDS, FITC-G4OS, and FITC-G5mDS (green) in brain tissue after i.n. administration. Bar $=50 \mu \mathrm{m}$.

i.n. with $0.1 \mathrm{mg} / \mathrm{kg} / \mathrm{bw} /$ day of G4mOS for 1 month showed visible signs of weakness and apathy during the second fortnight of treatment. Exposure to the two-object recognition test demonstrated no memory improvement in APP/PS1 mice after chronic treatment with G4mOS and G4mDS when compared with control APP/PS1 animals. In contrast, memory impairment was detected in WT mice after G4mOS treatment when compared with PBS- and G4mDS-treated WT animals (Figure 6J).

A $\beta$ plaque quantification in neocortex of APP/PS1 mice, as revealed by $\mathrm{A} \beta$ immunohistochemistry, showed significantly higher levels after chronic treatment with G4mOS and G4mDS when compared to APP/PS1 mice treated with PBS alone (Figure 6A,B). Quantification of the ThS-positive burden revealed that the levels of fibrillar component of $A \beta$ were significantly higher after treatment only with G4mOS when compared to APP/PS1 mice of the control group (Figure 6C,D). Fourier transform infrared microspectroscopy examination confirmed an elevated degree of aggregation (stronger amide I absorbance at $1630 \mathrm{~cm}^{-1}$ ) in plaques of G4mOStreated APP/PS1 mice when compared with nontreated agematched APP/PS1 mice. No significant changes were detected with G4mDS (Figure 6F,G).

One-way ANOVA and subsequent Tukey's post hoc test indicated a significant effect of age on the ratio of soluble $\mathrm{A} \beta(1-42)$ to $\mathrm{A} \beta(1-40)$, which was significantly higher in APP/PS1 mice of control group at 6 months of age when compared to APP/PS1 mice at 5 months $(p<0.05)$. After treatment of APP/PS1 mice with G4mOS and G4mDS, the ratio of soluble $\mathrm{A} \beta(1-42)$ to $\mathrm{A} \beta(1-40)$ was not significantly different when compared to APP/PS1 mice aged 5 months (Figure $6 \mathrm{H}$ ). Thus, G4mOS and G4mDS are able to promote the aggregation of soluble $\mathrm{A} \beta$ in APP/PS1 mice. This fact was also confirmed by a reduction in the expression of the $\sim 20 \mathrm{kDa}$ band of soluble $\mathrm{A} \beta$ after treatment with G4mOS and G4mDS in comparison to control mice observed in non-SDS PAGE (Figure 6I).

\section{DISCUSSION}

PPI glycodendrimers have been postulated as promising modulators of the formation of the amyloid fibrillar structures related to certain protein conformational diseases such as $\mathrm{AD}$ and prion diseases. ${ }^{6-13}$ The interaction of these dendrimers with amyloid peptides is established by hydrogen bonds and depends on the density of hydrogen bond-forming groups on the dendrimer surface. ${ }^{5}$ Thus, glycodendrimers can interact with $\mathrm{A} \beta$ peptides and, under certain conditions, can lock them into nontoxic glycofibrils. ${ }^{12}$

Successful candidates for $\mathrm{AD}$ treatment have not only to possess antiamyloidogenic properties, but also must have the capacity to cross the $\mathrm{BBB}$, modulate $\mathrm{A} \beta$ aggregation in vivo, and improve clinical symptoms. Here we explored, in vivo, the effect of electroneutral and cationic PPI maltose dendrimers of the fourth generation on APP/PS1 mice. Our objective was to assess whether locking soluble amyloid into glycofibrils can be beneficial in APP/PS1 transgenic mice, a model of brain amyloid deposition and $\mathrm{AD}$.

Our results confirmed that, under certain conditions, maltose-modified dendrimers are able to promote $\mathrm{A} \beta$ fibril formation, cleaning up the solution from small oligomeric aggregates. Moreover, small angle scattering results indicate that PPI glycodendrimers in phosphate buffered saline at $37^{\circ} \mathrm{C}$ are spherical macromolecules (up to $8.4 \mathrm{~nm}$ in diameter), but in spite of their size, PPI maltose dendrimers are able to penetrate into the cytoplasm of cultured cells. Vesicles in the cytoplasm of treated SH-SY5Y cells detected by synchrotron 

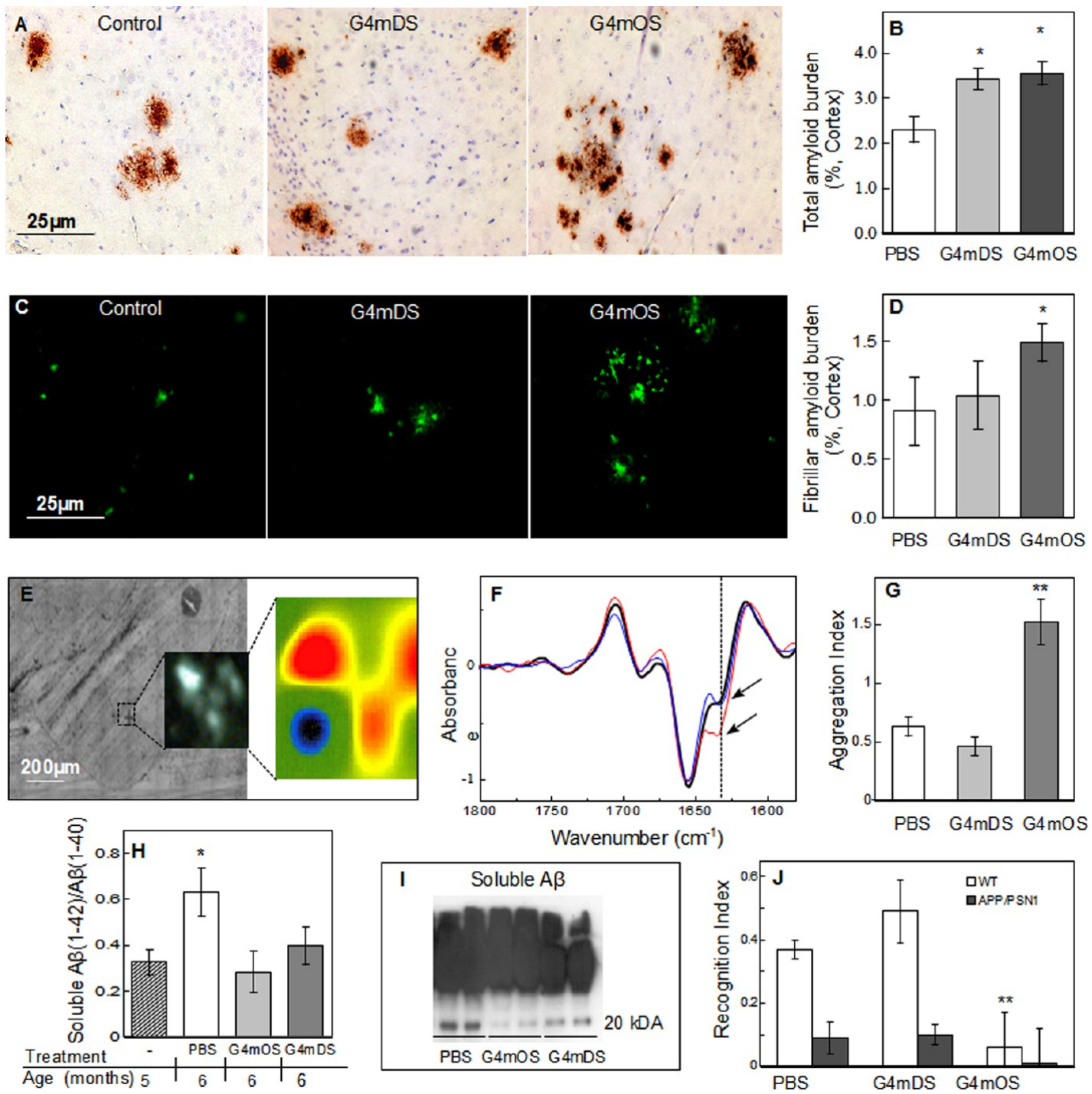

Figure 6. $\mathrm{A} \beta$ profile after chronic G4mDS and G4mOS treatment of APP/PS1 mice. (A) A $\beta$ immunohistochemistry showing more aggregated A $\beta$ plaques in mice treated i.n. with G4mOS when compared to PBS-treated mice. (B) Total $A \beta$ burden, calculated as the percentage of $A \beta$ amyloid deposition area with respect to the total cortex area, is significantly higher in G4mOS- and G4mDS-treated APP/PS1 mice compared with the control group of APP/PS1 mice. (C) ThS fluorescence microscopy images showing increased fibrillar A $\beta$ deposits after chronic treatment with G4mOS. (D) Total fibrillar amyloid burden, calculated as the percentage of the ThS-positive amyloid deposition area with respect to the total cortex area, was higher in G4mOS-treated APP/PS1 mice compared with the control group of APP/PS1 mice. (E) Representative FTIR microscope image of amida I absorbance in A $\beta$ plaques of APP/PS1 mice. The aggregation level of $\mathrm{A} \beta$ peptide in the plaques was modified after treatment with G4mDS and G4mOS compared with $\mathrm{A} \beta$ aggregation in the $\mathrm{A} \beta$ plaques of the control group. Bright field of neocortex and enlarged epifluorescence image of $\mathrm{A} \beta$ plaque detected in UV and (enlarged) infrared map of this plaque where the $\beta$-sheet content is red, the $\alpha$-structure is blue, and the surrounding white matter is green. (F) The absorbance of $1625 \mathrm{~nm}^{-1}$ band assigned to $\beta$-sheet increases after treatment with G4mOS (red spectra) and does not change after treatment with G4mDS (blue spectra), the control is shown by a black spectra, data expressed as a $2 \mathrm{nd}$ derivative. ${ }^{36}$ (G) A ratio between the peak corresponding to $\alpha$-helix and the peak corresponding to $\beta$-sheets indicates that the degree of aggregation of $\mathrm{A} \beta$ in plaques is significantly increased after chronic treatment with G4mOS. (H) ELISA quantification of $\mathrm{A} \beta(1-42)$ and $\mathrm{A} \beta(1-40)$; the ratio of $\mathrm{A} \beta(1-42)$ to A $\beta(1-40)$ is significantly increased in control animal group from the age of 5 to 6 months, whereas after treatment with G4mDS and G4mOS the ratio of $\mathrm{A} \beta(1-42)$ to $\mathrm{A} \beta(1-40)$ when compared to 5 -month-old animals was not modified. (I) $\mathrm{A} \beta$ immunoblot of APP/PS1 mice showing a reduction in the expression of the $20 \mathrm{kDa}$ band after treatment with G4mDS and G4mOS compared to the control group. (J) Memory performance in the V-maze shows significant differences between WT mice treated with G4mOS and corresponding control WT mice. G4mOS-treated WT mice have reduced memory capacities compared with animals treated with PBS or G4mDS. In contrast, no apparent effects on memory deterioration are observed in APP/PS1 transgenic mice following i.n. administration of dendrimers. Statistics: (B, D, G, H) one-way ANOVA followed by Tukey's post hoc test $(* * p<0.01, * p<0.05)$; (J) two-way ANOVA with genotype and treatment as between factors followed by Tukey's post hoc test $(* * p$ $<0.01)$. All data are expressed as a mean \pm SEM, $n=6$.

based cryo X-ray microscopy might be consistent with the active transport of dendrimers. Furthermore, this observation is in agreement with a previous cellular uptake study in which nonendocytotic and endocytotic uptake of cationic and neutral
PPI maltose dendrimers was identified in normal and cancer melanoma cell lines. ${ }^{38}$

The effect of maltose-decorated dendrimers on $\mathrm{A} \beta(1-42)$ toxicity, administered to cell cultures, shows a nontoxic profile in comparison to previous data, where only $\mathrm{G} 4 \mathrm{mDS}$ at 
micromolar concentrations favored the formation of nontoxic $\mathrm{A} \beta(1-40)$ fibrillar structures. ${ }^{12}$ Thus, we show here that at nanomolar concentrations G5mDS and G4mOS, but not G4mIIIDS, can induce the formation of fibrillar structures. This is further progress on the previous observation, ${ }^{12}$ giving rise to fibrillar structures using very low concentrated glycodendrimer. In a recent study, ${ }^{39}$ cationic polylysine dendrimers also prevented cell lysis of human neuroblastoma SH-SY5Y cells in the presence of $\mathrm{A} \beta$ peptides. Finally, this implies that several dendrimers may protect cell viability of SH-SY5Y cells against A $\beta$ peptides.

Cell viability assays have shown that brain tissue extracts without lesions in the presence of PPI glycodendrimers are not toxic to cells. Thus, nonspecific binding of dendrimers with brain tissue proteins is not harmful to cells. However, only electroneutral G5mDS and G4mDS reduced the toxicity of $\mathrm{AD}$ brain extracts on SH-SY5Y neuroblastoma cells. This result shows that G5mDS and G4mDS interact with native $\mathrm{A} \beta$ in spite of the presence of other proteins in $\mathrm{AD}$ brain extract. It is likely that strong electrostatic interactions between the positive charges on the cationic surface of G4mOS and G4m-IIIOS and the negatively charged elements present in brain extracts account for the effects of cationic PPI glycodendrimers on $\mathrm{AD}$ brain extracts.

To proceed with the experiments in vivo we selected electroneutral G4mDS and cationic G4mOS. G4m-IIIOS dendrimers were ruled out because they are not effective against $\mathrm{A} \beta(1-42)$ or $\mathrm{AD}$ brain tissue toxicity. G5mDS was excluded because the workable concentration range was considered to be too narrow for an in vivo study.

Doses of $10 \mathrm{mg} / \mathrm{kg} / \mathrm{bw} /$ day of electroneutral G4mDS and G5mDS do not cross the BBB after i.p. injection. Higher doses of G4mDS and G5mDS were not considered appropriate for chronic i.p. treatment because of a possible dendrimer-driven hemolysis. ${ }^{23}$ However, the same neutral dendrimers can reach the brain via i.n. administration, albeit in small quantities (about $6 \%$ of the total single dose). Cationic G4mOS can cross the $\mathrm{BBB}$ twice as well as neutral G4mDs and G5mDS due to the interaction between the cationic surface of dendrimers and the negatively charged proteins on the cell membrane. It was reported recently that cationic maltotriose PPI dendrimers can enter the CNS after i.p administration (about $4 \%$ of the total single dose $){ }^{28}$ Therefore, our result shows the i.n. route to be more effective than the i.p. route for cationic PPI glycodendrimers to cross the $\mathrm{BBB}$.

We report for the first time that G4mOS and G4mDS have an antiamyloidogenic effect, described previously in vitro, as well as being detectable in vivo. In treated APP-PS1 mice, the $\mathrm{A} \beta(1-40)$ and $\mathrm{A} \beta(1-42)$ soluble levels were not increased in comparison to those of APP/PS1 control animals receiving PBS during the treatment period. Specific effects of G4mOS and $\mathrm{G} 4 \mathrm{mDS}$ on $\mathrm{A} \beta$ aggregation have been observed in treated $\mathrm{APP} / \mathrm{PS} 1$ mice, including an increase in $\mathrm{A} \beta$ burden and fibrillar content. The changes in the aggregation level in $\mathrm{A} \beta$ after treatment were also confirmed by $\mu$ FTIR and native/PAGE.

In spite of these potentially beneficial effects, such as the capacity to cross the $\mathrm{BBB}$ and the anti- $\mathrm{A} \beta$ properties, memory performance in the $\mathrm{V}$-maze has shown no apparent memory improvements in APP/PS1 transgenic mice following G4mDS or G4mOS administration. Moreover, significant detrimental effects are observed in WT after chronic treatment with cationic G4mOS. This is a very important setback when considering the use of cationic PPI dendrimers in medical applications, for example, for brain delivery systems ${ }^{14,15}$ or gene transfection, in which dendrimers are used as nucleic acid carriers, and the charge is required for electrostatic interactions with DNA or RNA. $^{20}$ Modification of the surface by attaching maltose reduces the toxicity of PPI dendrimers, but this procedure is still not sufficient to improve memory deficits in APP/PS1 transgenic mice. The present study points to the need to refine the administration protocols and the characteristics of maltose dendrimers in order to improve their beneficial possibilities and reduce their potentially harmful effects.

\section{CONCLUSIONS}

First, at low concentrations maltose PPI dendrimers of fourth and fifth generation have the capacity to accelerate $\mathrm{A} \beta(1-40)$ peptide fibril formation. PPI maltose dendrimers are able to reduce the toxicity of $\mathrm{A} \beta(1-42)$ and $\mathrm{AD}$ brain extract in human neuroblastoma SH-SY5Y cells. Cationic maltotriose dendrimers cannot be used as antiamyloidogenic agents.

Second, maltose-modified PPI dendrimers are able to cross the BBB when administered i.n. to WT and APP/PS1 transgenic mice. G4mOS and G4mDS are able to modify the $\mathrm{A} \beta$ profile of APP/PS1 mice. However, G4mOS and G4mDS do not rescue memory impairment in APP/PS1 transgenic mice, and cationic G4mOS is harmful when chronically administered to WT mice. These observations point to the need to modify cationic PPI dendrimers before considering their use in medical applications.

\section{AUTHOR INFORMATION}

\section{Corresponding Author}

*E-mail: 8082ifa@gmail.com (I.F.); oklementieva@idibell.cat (O.K.).

\section{Notes}

The authors declare no competing financial interest.

\section{ACKNOWLEDGMENTS}

This study was funded by the Seventh Framework Programme of the European Commission, grant agreement 278486: DEVELAGE. O.K. is supported by this grant. We thank the Saxon Ministry of Science and Art (SMWK), the German Federal Ministry for Education and Science (BMBF), and the COST-Action Program TD0802 (biodendrimers in biomedical applications). We thank B. Torrejón-Escribano for his help with the microscopy, Dr. P. Guttman for his aid in X-ray and cryolight microscopy (BESSY), and T. Yohannan for editorial assistance.

\section{REFERENCES}

(1) Lansbury, P. T.; Lashuel, H. A. Nature 2006, 443, 774-779.

(2) Glabe, C. G. J. Biol. Chem. 2008, 283, 29639-29643.

(3) Schmit, J. D.; Ghosh, K.; Dill, K. Biophys. J. 2011, 100, 450-458.

(4) Caminade, A.-M.; Laurent, R.; Majoral, J.-P. Adv. Drug Delivery Rev. 2005, 57, 2130-2146.

(5) Fischer, M.; Appelhans, D.; Schwarz, S.; Klajnert, B.; Bryszewska, M.; Voit, B.; Rogers, M. Biomacromolecules 2010, 11, 1314-1325.

(6) McCarthy, J. M.; Franke, M.; Resenberger, U. K.; Waldron, S.; Simpson, J. C.; Tatzelt, J.; Appelhans, D.; Rogers, M. S. Plos One 2013, 8 , e55282.

(7) McCarthy, J. M.; Rasines Moreno, B.; Filippini, D.; Komber, H.; Maly, M.; Cernescu, M.; Brutschy, B.; Appelhans, D.; Rogers, M. S. Biomacromolecules 2013, 14, 27-37.

(8) McCarthy, J. M.; Rasines, B.; Appelhans, D.; Rogers, M. Adv. Healthcare Mater. 2012, 1, 768-772. 
(9) Klajnert, B.; Cladera, J.; Bryszewska, M. Biomacromolecules 2006, 7, 2186-2191.

(10) Klajnert, B.; Cortijo-Arellano, M.; Cladera, J.; Bryszewska, M. Biochem. Biophys. Res. Commun. 2006, 345, 21-28.

(11) Klajnert, B.; Cortijo-Arellano, M.; Bryszewska, M.; Cladera, J. Biochem. Biophys. Res. Commun. 2006, 339, 577-582.

(12) Klementieva, O.; Benseny-Cases, N.; Gella, A.; Appelhans, D.;

Voit, B.; Cladera, J. Biomacromolecules 2011, 12, 3903-3909.

(13) Benseny-Cases, N.; Klementieva, O.; Cladera, J. New J. Chem. 2012, 36, 211-216.

(14) Dai, H.; Navath, R. S.; Balakrishnan, B.; Guru, B. R.; Mishra, M. K.; Romero, R.; Kannan, R. M.; Kannan, S. Nanomedicine 2010, 5, 1317-1329.

(15) Beg, S.; Samad, A.; I. Alam, M.; Nazish, I. CNS Neurol. Disord.: Drug Targets 2011, 10, 576-588.

(16) Lemere, C. A. Prog. Brain Res. 2009, 175, 83-93.

(17) Byeon, S. R.; Kim, H. V.; Jeon, M.; Ahn, Y. G.; Kim, M. S.; Kong, J. Y.; Kim, H. Y.; Kim, Y. S.; Kim, D. J. Bioorg. Med. Chem. Lett. 2013, 23, 3467-3469.

(18) Wagner, J.; Ryazanov, S.; Leonov, A.; Levin, J.; Shi, S.; Schmidt, F.; Prix, C.; Pan-Montojo, F.; Bertsch, U.; Mitteregger-Kretzschmar, G.; Geissen, M.; Eiden, M.; Leidel, F.; Hirschberger, T.; Deeg, A. A.; Krauth, J. J.; Zinth, W.; Tavan, P.; Pilger, J.; Zweckstetter, M.; Frank, T.; Bähr, M.; Weishaupt, J. H.; Uhr, M.; Urlaub, H.; Teichmann, U.; Samwer, M.; Bötzel, K.; Groschup, M.; Kretzschmar, H.; Griesinger, C.; Giese, A. Acta Neuropathol. 2013, 125, 795-813.

(19) Svenson, S.; Tomalia, D. A. Adv. Drug Delivery Rev. 2005, 57, 2106-2129.

(20) Boas, U.; Heegaard, P. M. H. Chem. Soc. Rev. 2004, 33, 43-63.

(21) Klajnert, B.; Appelhans, D.; Komber, H.; Morgner, N.; Schwarz, S.; Richter, S.; Brutschy, B.; Ionov, M.; Tonkikh, A. K.; Bryszewska, M.; Voit, B. Chem.-Eur. J. 2008, 14, 7030-7041.

(22) Ziemba, B.; Janaszewska, A.; Ciepluch, K.; Krotewicz, M.; Fogel, W. A.; Appelhans, D.; Voit, B.; Bryszewska, M.; Klajnert, B. J. Biomed. Mater. Res. A 2011, 99, 261-268.

(23) Ziemba, B.; Halets, I.; Shcharbin, D.; Appelhans, D.; Voit, B.; Pieszynski, I.; Bryszewska, M.; Klajnert, B. J. Biomed. Mater. Res. A 2012, 100, 2870-2880.

(24) Ziemba, B.; Matuszko, G.; Bryszewska, M.; Klajnert, B. Cell. Mol. Biol. Lett. 2012, 17, 21-35.

(25) Abbott, N. J.; Rönnbäck, L.; Hansson, E. Nat. Rev. Neurosci. 2006, 7, 41-53.

(26) Huang, R.-Q.; Qu, Y.-H.; Ke, W.-L.; Zhu, J.-H.; Pei, Y.-Y.; Jiang, C. FASEB J. 2007, 21, 1117-1125.

(27) Wu, G.; Barth, R. F.; Yang, W.; Kawabata, S.; Zhang, L.; GreenChurch, K. Mol. Cancer Ther. 2006, 5, 52-59.

(28) Janaszewska, A.; Ziemba, B.; Ciepluch, K.; Appelhans, D.; Voit, B.; Klajnert, B.; Bryszewska, M. New J. Chem. 2012, 36, 350.

(29) Appelhans, D.; Oertel, U.; Mazzeo, R.; Komber, H.; Hoffmann, J.; Weidner, S.; Brutschy, B.; Voit, B.; Francesca Ottaviani, M. Proc. $R$. Soc. A 2010, 466, 1489-1513.

(30) Benseny-Cases, N.; Cócera, M.; Cladera, J. Biochem. Biophys. Res. Commun. 2007, 361, 916-921.

(31) Roessle, M. W.; Klaering, R.; Ristau, U.; Robrahn, B.; Jahn, D.; Gehrmann, T.; Konarev, P.; Round, A.; Fiedler, S.; Hermes, C.; Svergun, D. J. Appl. Crystallogr. 2007, 40, s190-s194.

(32) Konarev, P. V.; Volkov, V. V.; Sokolova, A. V.; Koch, M. H. J.; Svergun, D. I. J. Appl. Crystallogr. 2003, 36, 1277-1282.

(33) Svergun, D. I. Biophys. J. 1999, 76, 2879-2886.

(34) Schneider, G.; Guttmann, P.; Heim, S.; Rehbein, S.; Mueller, F.; Nagashima, K.; Heymann, J. B.; Müller, W. G.; McNally, J. G. Nat. Methods 2010, 7, 985-987.

(35) Aso, E.; Lomoio, S.; López-González, I.; Joda, L.; Carmona, M.; Fernández-Yagüe, N.; Moreno, J.; Juvés, S.; Pujol, A.; Pamplona, R.; Portero-Otin, M.; Martín, V.; Díaz, M.; Ferrer, I. Brain Pathol. 2012, 22, 636-653.

(36) Rak, M.; Del Bigio, M. R.; Mai, S.; Westaway, D.; Gough, K. Biopolymers 2007, 87, 207-217.
(37) Snyder, S. W.; Ladror, U. S.; Wade, W. S.; Wang, G. T.; Barrett, L. W.; Matayoshi, E. D.; Huffaker, H. J.; Krafft, G. A.; Holzman, T. F. Biophys. J. 1994, 67, 1216-1228.

(38) Filimon, A.; Sima, L. E.; Appelhans, D.; Voit, B.; Negroiu, G. Curr. Med. Chem. 2012, 19, 4955-4968.

(39) Neelov, I. M.; Janaszewska, A.; Klajnert, B.; Bryszewska, M.; Makova, N. Z.; Hicks, D.; Pearson, H. A.; Vlasov, G. P.; Ilyash, M. Y.; Vasilev, D. S.; Dubrovskaya, N. M.; Tumanova, N. L.; Zhuravin, I. A.; Turner, A. J.; Nalivaeva, N. N. Curr. Med. Chem. 2013, 20, 134-143. 